\title{
Um dispositivo para a gestão de descontinuidades no Rio de Janeiro: os ecolimites no plano diretor da cidade
}

\section{Ana Brasil Machado}

\section{Introdução}

O crescimento extensivo das cidades é considerado um problema central para o planejamento urbano contemporâneo, frequentemente associado a um amplo leque de custos ambientais e sociais. Foi nas décadas de 1960 e 1970, com a crise urbana e econômica e com a emergência do movimento ambientalista, que esta preocupação se tornou mais evidente. (BENGSTON, FLETCHER e NELSON, 2004). São inúmeros os exemplos de cidades que adotaram políticas públicas voltadas para a gestão do crescimento extensivo e para a proteção de espaços livres. Estas políticas se alinham às críticas ao modelo de cidade dispersa, responsável por maiores gastos energéticos e maiores demandas de infraestrutura, pelo aumento da duração dos deslocamentos diários e da poluição, e pela diminuição de áreas livres e de espaços públicos.

$\mathrm{Na}$ América do Sul, onde o crescimento urbano se caracterizou por um ritmo acelerado, pela predominância do setor terciário e pela informalidade (SANTOS, 1981), nota-se uma considerável densidade normativa relacionada ao tema, o que demonstra o interesse da política urbana em ordenar o fenômeno da expansão da cidade. Grandes cidades como Buenos Aires, Rio de Janeiro, Santiago, Montevidéu, Bogotá, Medellín e Quito elaboraram instrumentos neste sentido: zoneamentos, criação de espaços públicos e construção de limites físicos são alguns deles. Além disso, a produção de limites vincula-se a outras questões urbanas, tais como as ocupações ilegais, a preservação ambiental, a provisão de água, a proteção de paisagens naturais e culturais, a metropolização e a produção agrícola.

Em dezembro de 2008, começou a ser divulgado pela grande imprensa um projeto para a cidade do Rio de Janeiro conhecido como Ecolimites. O projeto tinha como objetivo declarado conter o crescimento das favelas sobre as áreas verdes da cidade. De acordo com Ícaro Moreno, presidente da Empresa de Obras Públicas do Estado do Rio de Janeiro (EMOP), "a ideia é proteger a comunidade de um lado e a Mata Atlântica do outro. Fica mais fácil a fiscalização e ajuda a dimensionar as ações nas comunidades". (O GLOBO, 28/03/09).

Os ecolimites deveriam ser instalados em onze favelas localizadas na Área de Planejamento 2, Zona Sul do Rio de Janeiro. Estes limites assumiriam a forma de muros de aproximadamente três metros

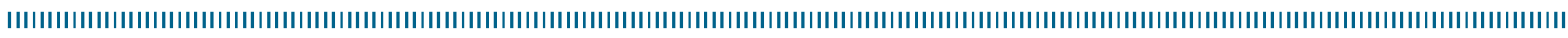
Como citar este artigo:

MACHADO, A. B. "Um dispositivo para a gestão de descontinuidades no Rio de Janeiro: os ecolimites no plano diretor da cidade”. In: RÜCKERT, A. A.; SILVA, A. C. P. da; SILVA, G. de V. (Orgs.). Geografia Política, Geopolítica e Gestão do Território: integração sul-americana e regiões periféricas. Porto Alegre: Editora Letra1, 2018 , p. 273-286 DOI 10.21507/9788563800367-17 
de altura e deveriam ser construídos ao longo das linhas de contato entre as favelas e as áreas a serem preservadas. Estes muros substituiriam os antigos marcos de concreto interligados por cabos de aço, também chamados ecolimites. Propostos pelo então secretário municipal de meio ambiente, Eduardo Paes, na gestão do prefeito Cesar Maia, a partir de 2001, foram instalados em mais de trinta favelas. Em 2004, Luis Paulo Conde, então secretário estadual na gestão da governadora Rosinha Garotinho, já havia proposto a construção de muros em favelas cariocas. No entanto, o projeto do arquiteto e vice-Governador foi "rechaçado pela mídia e pela opinião pública e, por isso, não foi levado adiante". (PEDROSO, 2010, p. 19).

O objetivo de conter a expansão das favelas sobre as áreas verdes, que norteava o projeto de 2008-2009, foi questionado, bem como o modelo de delimitação, amplamente relacionado à intenção de ampliar a segregação socioespacial na cidade. A implantação dos ecolimites foi tema de um intenso debate público. O limite ganhou distintos significados e estabeleceu relações espaciais entre formalidade e informalidade, natureza e artifício, áreas com o crescimento a ser contido e áreas de preservação. Funcionou como um objeto-síntese, capaz de concentrar diferentes questões pertinentes à cidade do Rio de Janeiro. Os significados associados ao debate concentraramse em três eixos principais: o da segregação, o da ordem/desordem e o da preservação ambiental. (MACHADO, 2009; 2011).

Desta maneira, o presente artigo se debruçou sobre o Plano Diretor de Desenvolvimento Urbano Sustentável do Município do Rio de Janeiro (Lei Complementar n. 111, de 1o de fevereiro de 2011) bem como sobre os documentos que ensejaram a sua formulação. A análise dos documentos foi feita a partir de uma leitura que guia, com base em uma ficha, que buscou compreender aspectos relativos aos aspectos morfológicos e comportamentais, além dos significados atribuídos aos ecolimites e seus congêneres, bem como às categorias espaciais mobilizadas e às interfaces produzidas. $\mathrm{O}$ artigo apresenta algumas questões metodológicas, a defesa de uma abordagem polifônica para o objeto espacial "ecolimite", uma breve descrição da evolução da produção dos ecolimites e a análise de sua elaboração no Plano Diretor.

\section{Como cercar o limite}

De um ponto de vista geográfico interessa investigar como são produzidos, material e simbolicamente, estes limites urbanos. Quais são as categorias espaciais mobilizadas e as interfaces construídas no âmbito da política de ecolimites e a quais questões urbanas ela se associa?

Partimos da ideia de que os limites urbanos podem assumir formas distintas, materializadas no terreno ou não, e que relacionam diversas categorias espaciais, e não apenas áreas urbanas e rurais. Os limites urbanos não se situam apenas na periferia das cidades, nas bordas externas, mas também no interior delas, marcando relações entre categorias espaciais que são consideradas componentes das cidades. Devem ser considerados em termos de suas dimensões morfológicas, dos usos sociais atuais ou prescritos, dos significados que lhes são atribuídos. E também em termos das interfaces que produzem, das estruturas normativas que os regulam, dos projetos urbanos que os concebem e desenham, dos atores envolvidos nas suas formulações, conflitos e negociações, dos problemas urbanos que lhes são associados e de suas possíveis relações com visões e modelos de cidade.

Considerando o acima exposto, propomos que os ecolimites sejam considerados como dispositivos, tais como definidos por Agamben, um dos mais importantes comentadores do pensamento de Foucault na atualidade. Muito embora não o tenha definido com clareza, Foucault se aproxima do conceito em uma entrevista concedida em 1977 :

Aquilo que estou tentando identificar com este nome é [...] um conjunto deliberadamente heterogêneo que comporta discursos, instituições, projetos arquitetônicos, regulamentações, leis, medidas administrativas, enunciados científicos, proposições filosóficas, morais, filantrópicas. Enfim, do dito e do não-dito, eis aqui os elementos do dispositivo. O dispositivo propriamente é a rede que estabelecemos entre estes elementos. [...] Por dispositivo entendo uma espécie, digamos, de 
formação que, em um dado momento, teve como função predominante responder a uma urgência. Deste modo, o dispositivo tem uma função estratégica dominante... (FOUCAULT apud AGAMBEN, 2007, p. 8-9).

Segundo Revel (2002), os dispositivos tratam tanto de discursos, como de práticas, instituições e táticas. Se tomarmos os ecolimites não como um discurso único ou mesmo como um único documento, e considerarmos que são compostos por notícias de jornal, regras urbanísticas, legislação ambiental, pesquisas científicas, julgamentos morais, projetos arquitetônicos, podemos dizer que os ecolimites se constituem nesta rede de elementos. Trata-se de discursos e práticas que possuem formas diversas, produzidos por diferentes sujeitos em variadas situações e voltados para múltiplas audiências. São elementos ou discursos que interagem, se justapõem, se afetam e se coadunam no sentido de responder a uma urgência, a uma questão: a gestão do crescimento urbano, na qual um dos elementos, no caso da cidade do Rio de Janeiro, é a gestão e criação de interfaces, notadamente entre áreas de preservação ambiental e as favelas.

A função de gestão assumida pelos ecolimites é característica fundamental dos dispositivos. Estes também apresentam a característica de se renovarem, se reajustarem, de acordo com as necessidades criadas por seus próprios efeitos. (CASTRO, 2004, p. 148). O dispositivo-ecolimites aqui composto é a rede resultante das disputas entre os diferentes enunciados considerados, é um mecanismo de fazer e desfazer interfaces. Cada um dos elementos que o compõe e cada etapa da implantação do projeto convocam e reformulam os termos do debate ou os dois lados dos limites. Por vezes, dialogam com categorias já existentes, territorialidades já constituídas para criar novos limites e territórios. Por outras, instituem novas categorias espaciais e reforçam limites já estabelecidos.

Desta maneira, os elementos foram investigados segundo as categorias espaciais mobilizadas, os limites apresentados e as interfaces produzidas. As categorias foram descritas em termos de sua morfologia, usos e ações e significados relacionados. Os limites, por sua vez, foram analisados segundo as suas funções, dimensão física, localização, significados e condições de implantação. Finalmente, as interfaces foram descritas a partir das categorias espaciais relacionadas, das descontinuidades e relações entre os sistemas espaciais.

\section{Em favor de uma abordagem polifônica dos ecolimites}

A partir da revisão bibliográfica acerca do tema dos ecolimites foi possível notar uma associação, quase unânime, entre a construção dos muros prevista no projeto dos ecolimites e a questão da segregação socioespacial. Longe de negar a importância deste debate, acredita-se que a formação de um consenso na interpretação do fenômeno contribui pouco para a sua compreensão. Partimos da hipótese de que os ecolimites concentram em sua formulação, implantação e discussão, outras questões também pertinentes à reflexão sobre a cidade.

Para a maior parte dos autores que se dedicaram ao tema ${ }^{1}$, o discurso ambiental que sustenta o projeto oculta os verdadeiros interesses dos ecolimites. Quando afirmam que o muro ou os ecolimites são objetos que criam e/ou reforçam a segregação socioespacial, a oposição valorizada é aquela entre cidade formal e cidade informal. Todos os outros significados atribuídos socialmente ao projeto ou mais especificamente ao muro do Santa Marta, são interpretados como falaciosos, desimportantes ou elitistas. A estes pesquisadores e analistas caberia revelar, desvelar, trazer à tona o real conteúdo do projeto.

Não se trata de dizer que a relação entre cidade formal e cidade informal, asfalto e favela, não é importante ou que não deva ser discutida, que não organiza também a vida na cidade. Mas sim de afirmar que a relação notadamente espacial entre cidade e natureza também deve ser problematizada. Neste artigo propomos que, para além do problema da segregação, os ecolimites atuam fundamentalmente na gestão do crescimento urbano.

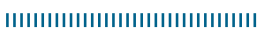

1 Por exemplo: Pedroso, 2010; Camargo, 2012; Cançado, 2009; Haesbaert, 2010; De Carli e Humanes, 2010 e Ferreira, 2009. 
Tendo em vista as especificidades da cidade do Rio de Janeiro, onde o contato entre espaço construído e ecossistemas naturais é especialmente valorizado, os ecolimites produzem e requalificam sistemas espaciais e descontinuidades (tais como definidas em 1967 por Roger Brunet, no texto Les phénoménes de discontinuité en Géographie) internas ao espaço urbano. Dada a centralidade da questão para a cidade, os ecolimites não são um instrumento isolado: muitos outros instrumentos também atuam no controle do crescimento urbano interno. Estes se apresentam como antecedentes e condições com as quais o projeto dialoga.

\section{O dispositivo-ecolimites: elementos e evolução}

No intuito de investigar as categorias espaciais mobilizadas na política de ecolimites do Rio de Janeiro, e como se constroem suas interfaces, nos pareceu interessante analisar o projeto não em um momento particular, mas enquanto um processo, que apresenta diferentes momentos, e é constituído por diferentes agentes e documentos. É importante ressaltar que não há "um documento Projeto Ecolimites", mas um conjunto de elementos que constituem a política, tais como o Projeto de Lei 245/2009, os projetos e desenhos específicos para os ecolimites construídos, declarações públicas de secretários envolvidos

Figura 1. Cabos de aço e pilares de concreto do projeto de 2001 (Favela do Rio Piraquê, em Guaratiba).

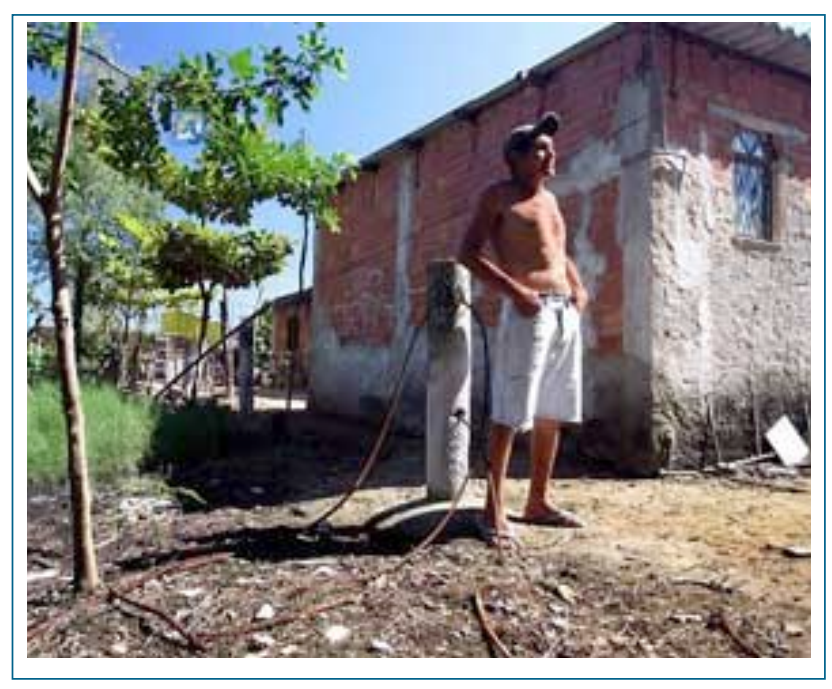

Fonte: O GLOBO, 23/05/2009. com o projeto e documentos relacionados ao Plano Diretor de Desenvolvimento Urbano Sustentável do Município do Rio de Janeiro, de 2011.

A cada vez que os delimitadores físicos, com suas morfologias e objetivos diversos, foram projetados no terreno, era produzida uma descontinuidade da evolução da política dos ecolimites. O ato de projetá-los, propô-los, construí-los, constituía um acontecimento que produzia um rearranjo no debate, nas formas, nos significados dos ecolimites. A cada anúncio, projeto, ou muro construído, um novo momento se desenvolvia. Neste sentido, o dispositivo-ecolimites pode ser entendido como uma composição de quatro momentos diferentes ${ }^{2}$.

Em 2001, o projeto foi concebido e implantado pela Prefeitura da Cidade, por meio da Secretaria Municipal de Meio Ambiente e consistia em marcos de concreto interligados por cabos de aço que foram instalados ao longo das linhas de contato entre as favelas e as áreas a serem preservadas em mais de trinta favelas.

Em 2004, o então vice-governador do Estado propôs a construção de muros que deveriam conter o crescimento das favelas e dificultar a ação de traficantes que utilizavam as matas vizinhas como rotas de fuga. Mesmo não tendo sido implantados naquele momento, os muros foram capazes de mobilizar um debate sobre a sua provável ineficiência e sobre os significados que carregavam.

Já em 2008, um grupo de secretários municipais anunciou a construção de ecolimites mais "robustos" que os antigos. Eles teriam a forma de muros de três metros de altura e seriam instalados em, pelo menos, onze favelas situadas na Zona Sul da cidade ${ }^{3}$, conforme podemos ver no mapa a seguir.

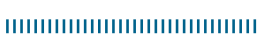

2 Os quatro momentos foram assim intitulados: "Eco-Limites: o programa de 2001"; "Um muro para a Rocinha"; "O valor da forma: o muro do Dona Marta, o Projeto de Lei 245/2009 e o Parque Ecológico da Rocinha", e "Os ecolimites no Plano Diretor de 2011". Para uma visão mais completa dos momentos, sugiro a leitura de minha dissertação (MACHADO, 2013), Disponível em: <http://objdig.ufrj.br/16/teses/811000.pdf〉.

3 Santa Marta (ou Dona Marta), Rocinha, Chapéu Mangueira, Benjamin Constant, Chácara do Céu, Parque da Cidade, Morro dos Cabritos, Tabajaras, Pavão-Pavãozinho, Cantagalo e Vidigal. 
Figura 2. Favelas que deveriam receber os ecolimites (Projeto 2008-2009).

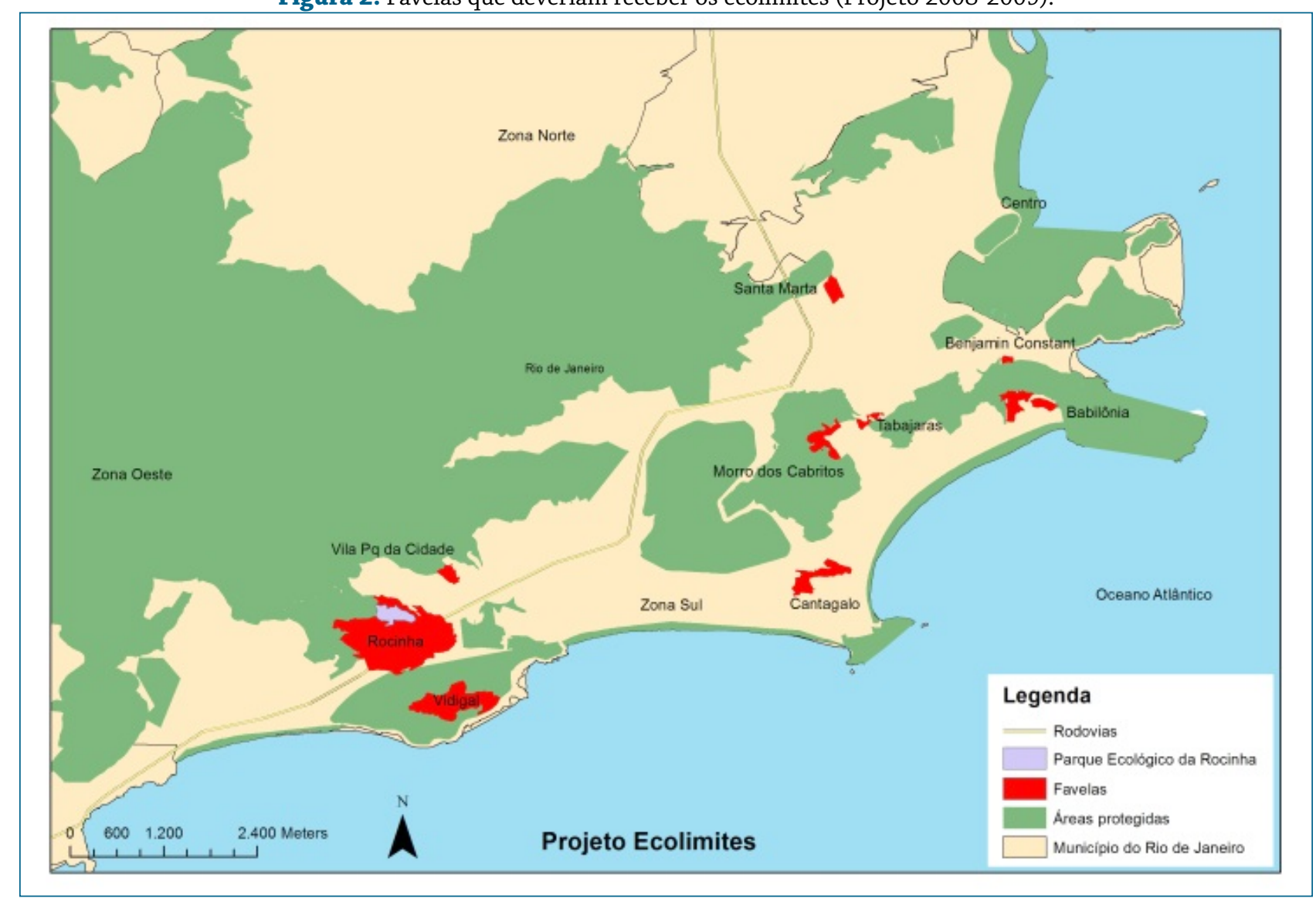

Fonte: O GLOBO/ MACHADO (2013); Organização: Marcos Góis.

O projeto tinha como objetivo declarado conter o crescimento das favelas sobre as áreas verdes da cidade. O primeiro deles foi construído na favela Santa Marta, na Zonal Sul da cidade, no ano de 2009. Nesta favela, foi construído um muro de concreto com cerca de 600 metros de extensão.

A implantação deste ecolimite foi tema de um intenso debate público. (MACHADO, 2009). $\mathrm{O}$ que esteve em questão foi a própria validade e necessidade da construção destes limites. O objetivo de contenção da expansão das favelas sobre as áreas verdes foi questionado, já que a primeira favela a receber o projeto apresentou decréscimo em sua área ${ }^{4}$ entre 1999 e 2004. Todavia, a maior parte da discussão se concentrou na questão formal dos limites: sua materialidade, sua forma de muro produziu diversas reações que quase sempre traziam à baila a grande carga simbólica deste tipo de objeto. Este debate público

| ||||||||||||||||||||||||||||||||||||||||

4 Conforme descrito por Cavallieri e Lopes (2006). colocou em jogo diversos valores e práticas sociais relacionadas à vida na cidade, à favela e às áreas de preservação ambiental. O limite, assim, ganhou distintos significados estabelecendo relações espaciais entre formalidade e informalidade, natureza e artifício na cidade.

Tão intensos foram os debates que o projeto criado para o ecolimite da Rocinha, a segunda favela a receber o projeto, teve de ser revisto e negociado. A favela da Rocinha possui uma população de aproximadamente 70 mil moradores e tem enorme visibilidade na cidade. $\mathrm{O}$ muro de três metros deu lugar a muretas baixas e alambrados e foi associado a um parque ecológico com diversos equipamentos para uso dos moradores da favela. Trata-se de uma composição de usos e formas, um misto de elemento de contenção da expansão horizontal da Rocinha, um parque ecológico e um espaço público de atividades orientadas.

Apenas estas duas favelas receberam as obras do projeto. No entanto, a pequena extensão 
Figura 3. Muro do Dona Marta.

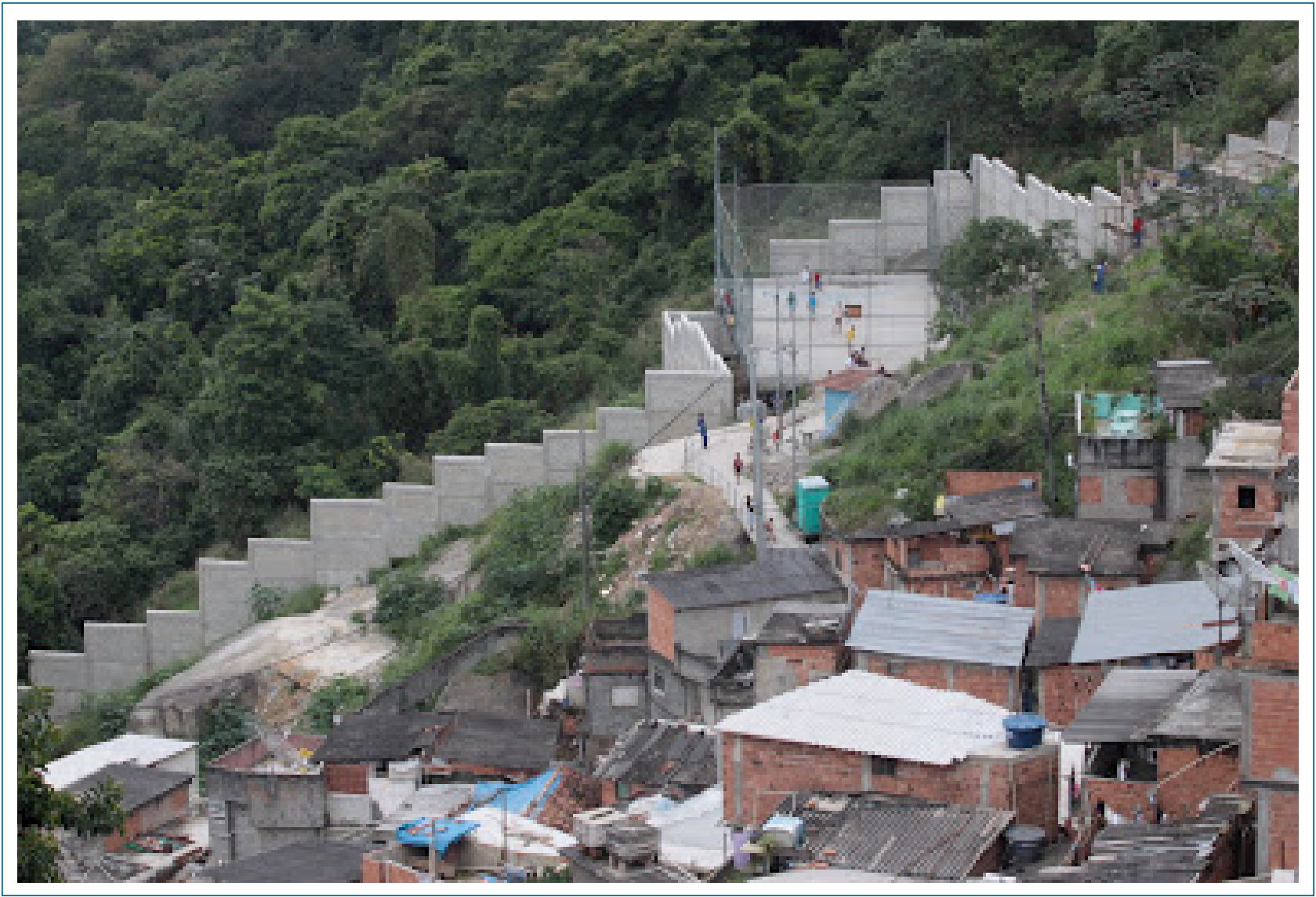

Foto: Zô Guimarães, Disponível em: <http://www.anf.org.br/o-muro-da-discordia/>.

Figura 4. Composição de formas do “novo” ecolimite da Rocinha, 2012.

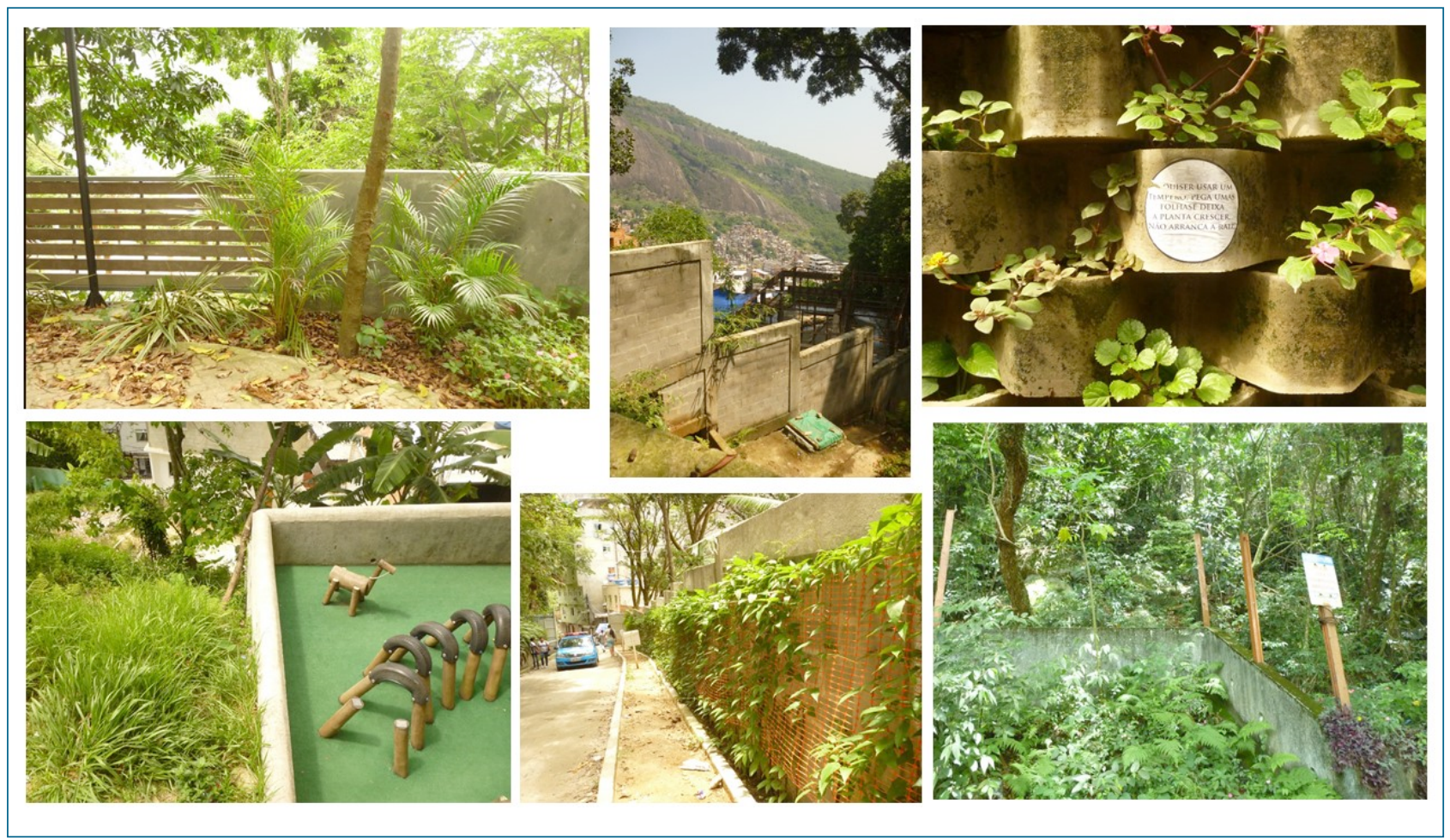

Fonte: Acervo da autora. 
edificada foi capaz de mobilizar diversos discursos sobre a cidade. $O$ debate também alcançou o poder legislativo da cidade do Rio de Janeiro, o que culminou na formulação de um projeto de lei (nunca aprovado) que, ao regulamentar os ecolimites, determinava que estes não poderiam ser materializados na forma de muros. Os ecolimites também foram debatidos no âmbito da tramitação do Plano Diretor, constituindo o quarto momento do dispositivo.

Cada um desses momentos, marcados por elementos capazes de produzir outros discursos, mobiliza categorias e interfaces distintas. Ao tomarmos em conta o conjunto dos momentos, acreditamos ser possível acompanhar estes movimentos entre universalizações e especificações no que diz respeito a categorias, limites e interfaces utilizados. Todavia, o objetivo aqui é o de descrever a formulação dos ecolimites no Plano Diretor da cidade do Rio de Janeiro.

\section{Os ecolimites no Plano Diretor de 2011}

Considerando o Plano Diretor como um importante instrumento na definição das políticas públicas e sua formulação como uma destacada arena do debate dos interesses referentes à política urbana na cidade do Rio de Janeiro, alguns documentos que marcam a sua evolução são constituídos neste trabalho como elementos do dispositivo-ecolimites. Isto porque a delimitação física das favelas/áreas verdes se constituiu como um tema relevante na concepção destes documentos, constando explicitamente em artigos e incisos.

Neste sentido, consideramos aqui o Plano Diretor de Desenvolvimento Urbano Sustentável do Município do Rio de Janeiro, de 2011, como um momento do debate acerca dos ecolimites. Momento este que é tributário da própria evolução do Plano Diretor da cidade e dos momentos precedentes já descritos anteriormente. A produção deste Plano Diretor é bastante complexa, combinando diferentes agentes e relações de poder e é também marcada por uma extensão temporal de aproximadamente 20 anos. Como aqui nossa intenção não é descrever o processo particular que deu origem a este documento, optou-se por identificar documentos de elevada importância em sua tramitação. Portanto, serão considerados: o Projeto de Lei Complementar $n^{\circ}$ 25/2001 (2001), o Projeto de Lei Complementar $n^{\circ}$ 25/2001- Substitutivo $n^{\circ}$ 3 (2006), o Anexo à Mensagem n ${ }^{\circ} 36 / 2009$ do Projeto de Lei Complementar $n^{\circ} 81 / 2001$ (2009) e o Plano Diretor de Desenvolvimento Urbano Sustentável do Município do Rio de Janeiro - Lei Complementar $n^{\circ} 111 / 2011$ (2011). Segue abaixo uma breve descrição destes elementos.

Em 1992, foi instituída a Lei Complementar n. 16, o Plano Diretor Decenal da Cidade do Rio de Janeiro, como um instrumento básico da política urbana do município. Em 2001, foi aprovado o Estatuto da Cidade (Lei 10.257 de 2001) que, dentre outras determinações, exigia que os planos diretores fossem revistos a cada dez anos. Em obediência à lei federal, o Executivo municipal encaminhou uma proposta de revisão à Câmara, o Projeto de Lei Complementar n 25/2001.

A dificuldade em realizar tal tarefa por corpo técnico formado exclusivamente por juristas, e os descontentamentos provocados no Legislativo e entre técnicos do próprio Executivo, corroborados pelo Ministério Público em atendimento à pressão popular encabeçada pelo Fórum de Acompanhamento do Plano Diretor, implicou a suspensão da apreciação do primeiro texto de revisão pelo Legislativo e sua devolução ao Executivo, tendo sido endereçado aos técnicos da Secretaria de Urbanismo, para consolidar a revisão. O documento original foi então fragmentado em diversas temáticas e entregue para os diferentes setores responsáveis que compõem o sistema de gestão urbana do município. (IPPUR, 2010, p. 10-11). ${ }^{5}$

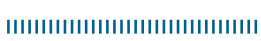

5 Em 2009, a Câmara Municipal do Rio de Janeiro, através da Comissão Especial do Plano Diretor, demandou ao Instituto de Pesquisa e Planejamento Urbano e Regional da Universidade Federal do Rio de Janeiro (IPPUR/UFRJ) uma análise das propostas de revisão do Plano Diretor então em curso. Em janeiro de 2010, foi divulgado o Relatório de avaliação técnica das propostas de revisão do Plano Diretor Decenal da Cidade do Rio de Janeiro (IPPUR, 2010). O documento é constituído por uma avaliação das propostas de revisão do Plano Diretor do Rio de Janeiro com base no Plano Diretor de 1992, no Substitutivo n 3 e no Anexo à Mensagem $n^{\circ} 36$ (2009). Está estruturado pela apreciação específica dos temas habitação, meio ambiente, transportes, gestão democrática e macrozoneamento, além de uma avaliação mais geral sobre a estrutura e conteúdo das propostas. 
Em 2005, foi criado, no âmbito do Executivo Municipal, um grupo de trabalho liderado pela Secretaria Municipal de Urbanismo cujo objetivo era coordenar e acompanhar o processo de revisão e alteração do Plano Diretor. A partir dos trabalhos deste grupo, foi encaminhada à Câmara Municipal a proposta de revisão denominada Substitutivo $\mathrm{n}^{\circ} 3$ ou Mensagem $\mathrm{n}^{\circ} 81 / 2001$ (que tem como base o Projeto de Lei no 25/2001), em 2006. Este documento constituiu a terceira proposta consolidada pelo poder público de modificação do documento que propôs a revisão do Plano Diretor da Cidade, elaborado em 2001. Ganhou destaque em relação aos outros substitutivos, constituindo importante base para a produção do texto aprovado em 2011.

Neste mesmo ano, foi criada a Comissão Especial de Revisão do Plano Diretor no âmbito da Câmara Municipal, que organizou o Seminário "Plano Diretor: o desafio da nova ordem jurídico-urbanística" a fim de fornecer subsídios aos parlamentares para a tarefa de revisão do Plano em questão.

O descontentamento com o texto do Substitutivo 3 angaria a adesão de técnicos e estudiosos alcançando até mesmo setores do próprio executivo, como demonstram as várias tentativas de paralisação do processo por representações da sociedade civil, e o encaminhamento da proposta de revisão naquilo que o interessa, consolidada nas 44 emendas do Anexo à Mensagem No 36. (IPPUR, 2010, p. 11).

Em 2009, uma nova comissão foi criada pelo executivo municipal a fim de readequar a proposta do Substitutivo $\mathrm{n}^{\circ} 3$ às alterações na legislação. (PREFEITURA DA CIDADE DO RIO DE JANEIRO, 2009). Neste processo participaram quadros ligados à Prefeitura e, posteriormente, foram acrescentadas propostas formuladas por vereadores envolvidos com a tramitação do Plano Diretor na Câmara, o que deu origem ao Anexo à Mensagem supracitado (trata-se da Mensagem 81/2001, o Substitutivo 3). Finalmente, em fevereiro de 2011, foi aprovada a revisão do Plano Diretor (Lei Complementar $n^{\circ}$ 111/2011), que passou a ser denominada Plano Diretor de Desenvolvimento Urbano Sustentável do Município do Rio de Janeiro.
No texto de 2001 (Projeto de Lei Complementar $n^{\circ} 25 / 2001$ ), podem ser identificados os seguintes limites: limites para a expansão urbana ${ }^{6}$ e demarcação física dos limites da área de expansão da Favela ${ }^{7}$. Para o primeiro limite o objetivo é controlar a ocupação das encostas. Para o segundo os objetivos são: deter o processo de superadensamento das Favelas e de exploração imobiliária na locação de imóveis nas comunidades e impedir a edificação de novas construções de qualquer natureza para além dos limites estabelecidos. Para ambos os limites não há uma definição sobre a dimensão física, mas para o segundo fica clara a intenção de materializá-lo no terreno. Os limites para a expansão urbana se localizam em encostas e sua fixação deve considerar a especificidade de cada área e os riscos de desmoronamento ou deslizamento identificados. Conforme o título da Subseção que o descreve, trata-se de uma ação compreendida no âmbito do Programa de Proteção de Encostas e Baixadas Sujeitas a Inundação. Já a demarcação física dos limites da área de expansão da Favela localizase mais especificamente em favelas e nas suas áreas de expansão. Neste documento não há a mobilização do significante "ecolimites".

No Substitutivo $\mathrm{n}^{\circ} 3$, de 2006, nota-se a utilização do termo eco-limites, que assinalam a fronteira entre favelas e áreas verdes protegidas ${ }^{8} \mathrm{e}$, conforme o Anexo III, devem promover a proteção ambiental. Neste mesmo Anexo, Diretrizes por Macrozona de Ocupação, os eco-limites são citados apenas na parte dedicada à Macrozona de Ocupação Controlada, o que indica que os eco-limites só deveriam ser implantados nesta Macrozona ${ }^{9}$.

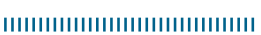

6 Título VII: Das políticas setoriais; Capítulo I: Da política de meio ambiente e valorização do patrimônio cultural; Seção IV: Dos programas; Subseção III: Do programa de proteção das encostas e das baixadas sujeitas a inundação, Art. 137, alínea I.

7 Título VIII: Disposições finais; Art. 238, par. $3^{\circ}$, alínea II.

8 Título II: Da Ordenação do território; Capítulo I: Do uso e da ocupação do solo; Seção II: Da ocupação urbana;Art. 11, inciso VII

9 A Macrozona de Ocupação Controlada compreende os bairros de Paquetá, Santa Teresa, Flamengo, Glória, Catete, Laranjeiras, Cosme Velho, Botafogo, Humaitá, Leme, Copacabana, Ipanema, Leblon, Jardim Botânico, Gávea, Lagoa, Vidigal, São Conrado, Rocinha, Urca e Alto da Boa Vista. 
Também é utilizado o termo limites físicos ${ }^{10}$, que estão orientados para conter $o$ crescimento $e$ expansão das favelas e devem se coadunar com o estabelecimento de regras urbanísticas especiais para que produzam a contenção do crescimento horizontal das favelas. O texto trata ainda das limitações estabelecidas para as áreas de restrição urbana ${ }^{11}$, que devem ser respeitadas nos processos de ocupação e crescimento da cidade.

No Anexo à Mensagem $n^{\circ} 36$, publicado em 2009, os Eco-limites constituem a fronteira entre as áreas ocupadas e as de proteção ou que apresentam cobertura vegetal de qualquer natureza ${ }^{12}$ e devem coibir a expansão urbana irregular sobre áreas que apresentem cobertura vegetal de qualquer natureza. ${ }^{13}$ Assim como no texto do Substitutivo $\mathrm{n}^{\circ} 3$, os ecolimites deverão ser implantados na Macrozona de Ocupação Controlada no intuito de promover a proteção ambienta ${ }^{14}$. Sua instalação deve estar associada a mecanismos de controle que garantam a obediência aos delimitadores físicos ${ }^{15}$.

Neste documento, bem como no Substitutivo $\mathrm{n}^{\circ} 3$, são descritas com as mesmas características e no mesmo artigo as limitações estabelecidas para as áreas de restrição à ocupação urbana. É apresentada também a cota de cem metros, que tem como fim a conservação e recuperação ambiental do Bioma de Mata Atlântica ${ }^{16}$. Este limite define as áreas acima da cota em que é vedada a abertura de logradouros bem como a implantação de loteamentos ou

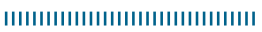

10 Título I: Da política urbana; Capítulo I: Dos princípios e diretrizes da política urbana do município Art. $3^{\circ}$, inciso VI.

11 (Título II: Da Ordenação do Território, Capítulo I: Do Uso e Ocupação do Solo, Seção II: Da Ocupação Urbana, Art. 9.

12 Título II: Da Ordenação do Território, Capítulo I: Do Uso e Ocupação do Solo, Seção II: Da Ocupação Urbana, Art. 11, par. $1^{\circ}$, inciso VII.

13 Título V: Das Estratégias de Implementação, Acompanhamento e Controle do Plano Diretor, Capítulo VI: Do Sistema de Controle de Uso e Ocupação do Solo, art. Sem número, inciso V.

14 Anexo III: Diretrizes por Macrozona de Ocupação.

15 Título V: Das Estratégias de Implementação, Acompanhamento e Controle do Plano Diretor, Capítulo VI: Do Sistema de Controle de Uso e Ocupação do Solo, art. Sem número, inciso V.

16 Título III: Dos Instrumentos de Política Urbana, Capítulo I: Dos Instrumentos Gerais de Regulação Urbanística, Seção II: Da Lei de Uso e Ocupação do Solo, art.34, par. $1^{\circ}$, inciso I. arruamentos de iniciativa particular ${ }^{17}$. Outro limite descrito é a cota de sessenta metros ${ }^{18}$ que determina que as intervenções em áreas acima desta em todo o município deverão considerar as restrições ambientais, paisagísticas e geotécnicas. Ainda no Anexo à Mensagem n ${ }^{\circ} 36$ é apresentado o limite delimitadores físicos georeferenciados ${ }^{19}$. Sua implantação é uma das ações estruturantes relativas à proteção do Bioma Mata Atlântica e tem como objetivo a proteção da Mata Atlântica e de outras áreas de relevância ambiental.

A Lei Complementar $n^{\circ} 111 / 2011$, que institui o Plano Diretor de 2011, apresenta novamente o limite denominado ecolimite ${ }^{20}$. Não há qualquer diferença de conteúdo e forma relacionadas aos ecolimites se compararmos o texto desta lei ao texto do Anexo à Mensagem n ${ }^{\circ} 36$, o que inclui sua localização na Macrozona de Ocupação Controlada. A única diferença reside na numeração do artigo que, no entanto, encontra-se nos mesmos Títulos, Capítulos e Seções. O mesmo acontece para os delimitadores físicos georeferenciados ${ }^{21}$ (há diferença apenas na numeração da subseção e do artigo) e para os limites físicos (a diferença está na numeração do inciso).

Assim como o Anexo n ${ }^{\circ} 36$, o texto de 2011 também descreve o limite cota de cem metros, que tem como fim a conservação e recuperação ambiental do Bioma de Mata Atlântica. Todavia, no texto mais recente, não são tratadas as restrições à abertura de logradouros, loteamentos

IIIIIIIIIIIIIIIIIIIIIIIIIIIIIIIIIIII

17 Título III: Dos Instrumentos da Política Urbana, Capítulo IV: Dos Instrumentos de Gestão Ambiental e Cultural, Seção I: Dos Instrumentos de Gestão Ambiental, Subseção V: Do Controle e Monitoramento Ambiental, art. Sem número, par. $1^{\circ}$ e $2^{\circ}$.

18 Título III: Dos Instrumentos da Política Urbana, Capítulo IV: Dos Instrumentos de Gestão Ambiental e Cultural, Seção I: Dos Instrumentos de Gestão Ambiental, Subseção V: Do Controle e Monitoramento Ambiental, art. Sem número.

19 Título IV: Das Políticas Setoriais, Capítulo II: Da Política de Meio Ambiente, Seção III: Das Ações Estruturantes, Subseção V: Da Proteção do Bioma Mata Atlântica, art. Sem número, inciso VII.

20 Título II: Do ordenamento territorial; Capítulo I: Do uso e ocupação do solo; Seção II: Da ocupação urbana; art. 15 par. $1^{\circ}$, inciso VII.

21 Título IV: Das políticas públicas setoriais; Capítulo II: Da política de meio ambiente; Seção III: Das ações estruturantes; Subseção V: Da proteção do Bioma Mata Atlântica; Art. 178, inciso VIII. 
e arruamentos. As limitações estabelecidas para as áreas de restrição à ocupação urbana e a cota de sessenta metros, presentes em 2009, não constam no texto mais recente.

Sobre as categorias espaciais mobilizadas pelos limites constituídos nos elementos que compõem este momento do dispositivo temos que, no texto de 2001, as categorias diretamente mobilizadas pela demarcação física dos limites da área de expansão da Favela são: área de expansão da favela e área florestada do entorno da favela. A área de expansão da favela deve ter seus limites demarcados fisicamente e, para além dos limites desta área de expansão não serão permitidas edificações de qualquer natureza. As favelas ${ }^{22}$ são caracterizadas pela precariedade da infraestrutura urbana e serviços públicos e valores associados à irregularidade e ilegalidade. Sua morfologia é marcada por vias estreitas e de alinhamento irregular, lotes de tamanho e forma irregulares e construções não licenciadas, em desconformidade com os padrões legais. Tratase de áreas predominantemente habitacionais ocupadas por população de baixa renda, que devem ser urbanizadas e regularizadas. Por outro lado, a área florestada do entorno da favela é suscetível à invasão e deve ser objeto de um sistema de contenção e prevenção de invasão.

Considerando a área de expansão da favela e a área florestada do entorno da favela, temos que estes sistemas espaciais estão situados nos limites externos das favelas e em justaposição. A interface produzida pelo limite acima descrito coloca em relação as favelas tanto com sua área de expansão como com a área florestada de seu entorno: o crescimento das favelas cria a sua própria área de expansão e pressiona a área florestada do seu entorno. É evidente que outras categorias que se associam a este limite e às categorias mobilizadas são descritas no documento. São elas: áreas destinadas à proteção do meio ambiente, Maciço da Tijuca, Parque Nacional da Tijuca, área de notável valor paisagístico, unidade de conservação ambiental, ocupação urbana e ocupação das encostas.

||IIIIIIIIIIIIIIIIIIIIIIIIIIIIIIIII

22 Título VII: Das políticas setoriais; Capítulo II: Das políticas habitacionais; Seção IV: Dos programas; Subseção I: Dos programas de urbanização e regularização fundiária das favelas; Art. 153 e 154.
No Substitutivo $\mathrm{n}^{\circ} 3$, os eco-limites mobilizam as categorias favelas e áreas verdes protegidas. As favelas têm sua morfologia marcada pelo crescimento e expansão, que devem ser contidos através da fixação de limites físicos e estabelecimento de regras urbanísticas especiais ${ }^{23}$. Devem sofrer recuperação das condições ambientais, implantação de infra estrutura e melhoria das condições de salubridade e habitabilidade das habitações ${ }^{24}$. Não constituem parte do tecido formal da cidade, devendo ser modificadas em sua forma urbana para que passem a integrá-lo. Tratase de áreas predominantemente habitacionais, caracterizadas por ocupação clandestina e de baixa renda ${ }^{25}$. Em comparação com o texto de 2001, as favelas ganham este atributo da clandestinidade de sua ocupação.

Já as áreas verdes protegidas são áreas externas aos eco-limites, onde não são permitidas construções. Devem ser protegidas e são definidas como áreas consideradas impróprias pela administração municipa ${ }^{26}$. A interface entre favelas e áreas verdes protegidas, categorias relacionadas pelos ecolimites, é caracterizada pela possível expansão das favelas sobre as áreas protegidas. Clandestina e informalmente as favelas crescem com novas construções e pressionam as áreas externas aos eco-limites, onde não são permitidas edificações.

De acordo com o relatório técnico produzido pelo Instituto de Planejamento Urbano e Regional, o Substitutivo 3 é marcado por um "naturalismo" por conceber o meio ambiente como um valor em si mesmo. Desta operação decorreria uma valoração negativa das favelas e loteamentos de baixa renda:

Esta opção conceitual, em certa medida, é o que legitimaria a definição de um novo 'mal ambiental' não mais situado nas atividades industriais, o trânsito, a destinação inadequada dos resíduos sólidos, a

||||||||||||||||||||||||||||||||||||

23 Título I: Da política urbana; Capítulo I: Dos princípios e diretrizes da política urbana do município, Art. $3^{\circ}$, inciso VI.

24 Título IV: Das políticas públicas setoriais; Capítulo IV: Da política de habitação; Seção I: Dos Objetivos, Art. 150, alínea V.

25 Título III: Dos instrumentos da política urbana; Capítulo VII: Da política de regularização urbanística e fundiária; Seção III: Dos Procedimentos, Art. 174, § $3^{\circ}$.

26 Título II: Da Ordenação do território; Capítulo I: Do uso e da ocupação do solo; Seção II: Da ocupação urbana; Art. 11. 
poluição atmosférica e outros problemas correlatos, mas as ocupações urbanas consideradas 'predatórias', especialmente as favelas e loteamentos de baixa renda. (IPPUR, 2010 p. 59).

Tanto no Anexo à Mensagem n ${ }^{\circ} 36$, de 2009, como no Plano Diretor de Desenvolvimento Urbano Sustentável do Município do Rio de Janeiro, de 2011, os ecolimites mobilizam explicitamente as categorias espaciais áreas ocupadas, expansão urbana irregular e áreas destinadas à proteção ambiental ou que apresentem cobertura vegetal de qualquer natureza. Nestes textos, as áreas ocupadas ou comprometidas com a ocupação são descritas como aquelas em que o uso e ocupação devem ser regulados pela limitação das densidades, da intensidade de construção e das atividades econômicas, em função da capacidade da infraestrutura, da rede de transportes e acessibilidade e da proteção ao meio ambiente natural e da memória urbana ${ }^{27}$. No texto de 2011 é acrescentado o direito de fruição à paisagem, natural da Cidade e da qualidade da ambiência urbana ${ }^{28}$.

Estas áreas ocupadas não são caracterizadas em termos de regularidade, formalidade ou legalidade. Neste sentido, os ecolimites estariam voltados a qualquer tipo de área ocupada, ocupação urbana ou área efetivamente ocupada e não especificamente às favelas, como no texto do Substitutivo $n^{\circ} 3$. Há de se considerar que esta mudança relativa às categorias espaciais mobilizadas modifica enormemente o conteúdo do próprio limite denominado ecolimite.

As áreas destinadas à proteção ambiental ou que apresentem cobertura vegetal de qualquer natureza devem ser protegidas com o auxílio dos delimitadores físicos e de mecanismos que garantam a sua obediência. Podem ser associadas a outras categorias espaciais tais como as descritas a seguir. As áreas objeto de proteção ambiental são aquelas que possuem características ambientais que devem ser preservadas da ocupação urbana. A Zona

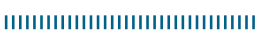

27 Título II: Da Ordenação do Território, Capítulo I: Do Uso e Ocupação do Solo, Seção II: Da Ocupação Urbana, Art. $10^{\circ}$.

28 Título II: Do ordenamento territorial; Capítulo I: Do uso e da ocupação do solo; Seção II: Da ocupação urbana art. 14. de Conservação Ambiental apresenta características naturais, culturais e/ ou paisagísticas relevantes para a preservação. Trata-se de áreas situadas acima da cota 100, das zonas de amortecimento e das áreas frágeis de baixada e de encosta e seus biomas associados, não ocupadas ou urbanizadas. Pode ser transformada total ou parcialmente em Unidade de Conservação da Natureza e possui atributos que justificam a sua preservação. As Unidades de Conservação da Natureza são delimitadas no ato de sua instituição, que é entendida como um instrumento básico para a proteção do meio ambiente do município.

Já as Áreas de Preservação Permanente deverão ser prioritariamente recuperadas mediante implementação de programas de recuperação e de revegetação. Sua instituição também é considerada um instrumento básico para a proteção do meio ambiente do município. As áreas impróprias à ocupação urbana constituem o ambiente natural, e devem ser preservadas da ocupação urbana. Assim como as florestas e demais áreas com cobertura vegetal é um elemento que condiciona a ocupação urbana.

O limite intitulado limites físicos, presente no Anexo à Mensagem n ${ }^{\circ} 36$ e no Plano Diretor de 2011, tem a função de conter o crescimento de favelas. Neste sentido, se diferencia dos ecolimites por mobilizar a categoria espacial favelas. Estas são caracterizadas pela precariedade da infraestrutura e dos serviços públicos, pelas vias estreitas, alinhamento irregular, e construções não licenciadas. Seu crescimento e expansão devem ser contidos através da fixação de limites físicos e estabelecimento de regras urbanísticas especiais. São áreas predominantemente habitacionais, caracterizadas por ocupação clandestina e de baixa renda (assim como Substitutivo $n^{\circ} 3$, de 2006). Devem ser integradas às áreas formais da Cidade, salvo se estiverem em situação de risco ou de proteção ambiental. No texto de 2011, à categoria é adicionada a informação de que todo o seu potencial turístico deve ser aproveitado.

De uma maneira geral, é possível afirmar que os agentes participantes deste momento do dispositivo-ecolimites são aqueles que participaram do debate da revisão do Plano Diretor 
Decenal do Rio de Janeiro, de 1992. São prefeitos, secretários de Urbanismo, Meio Ambiente, de Obras, de Habitação, etc, quadros técnicos da Prefeitura. São vereadores, membros de comissões especiais ligadas à formulação do Plano ou não. São cidadãos participantes das audiências, palestras e de manifestações que paralisaram o trâmite da revisão, bem como representantes das mais diversas associações da sociedade civil.

Em síntese, sobre os ecolimites na evolução do Plano Diretor, que culmina na aprovação do texto de 2011, é possível afirmar que o termo é utilizado a partir do documento de 2006, quando o projeto já tinha sido implementado em diversas situações e é empregado até 2011. No documento de 2001, apesar de já terem sido anunciados alguns meses antes, os ecolimites não figuram enquanto categoria. São outros os limites utilizados (limites para a expansão urbana, que trata das ocupações em encostas e demarcação física dos limites da área de expansão da Favela) que, de alguma maneira, já indicam as interfaces sobre as quais os ecolimites também operarão. Destaca-se que a questão da expansão das favelas aparece mais claramente já nas Disposições finais do Projeto de Lei.

No texto de 2006, os ecolimites compõem a interface entre favelas e áreas verdes. Nos documentos de 2009 e 2011, a categoria favela não é mais mobilizada diretamente pelos ecolimites, sendo substituída por áreas ocupadas. Por sua vez, as áreas verdes são substituídas por áreas destinadas à proteção ambiental ou que apresentem cobertura vegetal de qualquer natureza. O limite que mobilizará a categoria favela nestes dois últimos elementos (2009 e 2011) é denominado limites físicos, o mesmo já utilizado no Substitutivo de 2006, com iguais atributos.

As categorias espaciais mobilizadas pelas interfaces produzidas neste momento do dispositivo são dotadas de uma significativa generalidade. Não tratam de recortes específicos no terreno da cidade do Rio de Janeiro, embora sejam identificadas e qualificadas em termos de suas morfologias, usos e ações e valores associados. A categoria mais específica mobilizada diretamente pelo ecolimite é Macrozona de Ocupação
Controlada, que corresponde a uma grande porção do território municipal, composto pelas Áreas de Planejamento 1 e 2. Na tentativa de classificar em grandes grupos as categorias mobilizadas e acima descritas, é possível dizer que elas se dividem entre aquelas que devem ser objeto de contenção e aquelas que, por apresentarem relevantes atributos ambientais, devem ser preservadas.

Neste momento, os ecolimites dialogam com importantes questões para a cidade do Rio de Janeiro. O crescimento das favelas associa-se à ameaça ao meio ambiente urbano, à degradação de áreas que oferecem serviços ambientais à cidade, ao risco à própria favela quando esta ocupa terrenos instáveis ou que são severamente desmatados, à perda de qualidade de vida pela redução de espaços livres e áreas verdes. Além destas relações de cunho "ambientalista", o crescimento das favelas está fortemente ligado a problemas de "desordem urbana”. A favela, irregular, ilegal, informal, precária, pobre, clandestina, desordenada, ao crescer, estenderia por outras áreas da cidade as formas, usos e valores que a caracterizam enquanto categoria espacial.

\section{Considerações finais}

De maneira geral, os documentos selecionados para comporem o percurso recente do Plano Diretor da Cidade do Rio de Janeiro apresentam dois objetivos para os limites materializados no terreno. O primeiro é o de controlar a ocupação de encostas, de modo a preservar "áreas naturais". O segundo objetivo associado é o de controle do adensamento das favelas, caracterizadas pela irregularidade, para coibir o processo de exploração imobiliária "nas comunidades".

Considerando a Lei Complementar de 2011, é interessante notar a dissociação entre o termo favela e o termo ecolimites. Este passa a se associar às categorias áreas ocupadas e as destinadas à proteção ambiental, o que denota uma generalização da interface, sugerindo que os ecolimites poderiam ser construídos em qualquer tipo de área de ocupação, incluindo porções ocupadas pela população de alta renda. 
Esta dissociação vincula-se ao importante debate público acerca dos ecolimites. Neste debate, o caráter discriminatório da política de ecolimites foi colocado em questão, uma vez que edificações para a população de alta renda também se situam em áreas de proteção ambiental. Esta mudança atesta, portanto, a capacidade de renovação do dispositivo- ecolimites, no qual os elementos dialogam entre si e precisam ser reajustados.

Até os dias atuais, apenas Santa Marta e Rocinha receberam as obras do projeto, a despeito do objetivo de implantação de onze quilômetros de muros. No entanto, a pequena extensão edificada foi capaz de mobilizar diversos discursos sobre a cidade. $\mathrm{O}$ aparente esvaziamento da materialidade deu lugar a uma forte disputa no campo das ideias e foi retomado como objeto de tensão. Apenas enunciar a materialização de um limite ou de um muro em um determinado lugar tem força de mobilizar o debate público, de produzir instrumentos normativos e projetos urbanísticos, de convocar categorias espaciais, e concentrar questões estruturantes da cidade do Rio de Janeiro.

Tomando os limites não apenas como marcos de segregação, mas como elementos que operam nas relações entre os sistemas espaciais, é possível compreendê-los em uma perspectiva mais ampla, que abrange outras interações espaciais. $\mathrm{O}$ ato de limitar é um ato de diferenciação, seja com base na morfologia, nos usos ou significados atribuídos aos recortes espaciais que por ele são criados. Os limites agem para a reelaboração destas dimensões e, portanto das próprias categorias que colocam em relação. Considerados como um dispositivo, estes limites fazem e desfazem interfaces ao mobilizar e requalificar categorias espaciais. Os documentos aqui descritos se relacionam, se afetam e se encontram no sentido de responder à urgência determinada como a gestão do crescimento da cidade.

\section{Referências}

AGAMBEN, Giorgio. Qué es un dispositivo? Sociológica, ano 26, n. 73, 2011, p. 249-264

BENGSTON,D. FLETCHER, J. e NELSON,K. Public policies for managing urban growth and protecting open space: policy instruments and lessons learned in the United States. Landscape and Urban Planning, n. 69, 2004, p. 271-286
BRUNET, Roger. Les phénoménes de discontinuité en Géographie. Mémoires et documents, n. 7, 1967.

CAMARGO, Jean Carlos. Ecolimites ou Sóciolimites: da "preservação ambiental" à segregação sócio-espacial?, 2012. Disponível em: <http:// observatoriodasmetropoles.net/index. php? option =com_ k2\&view=item\&id=147:ecolimites-ou-s\%C3\%B3ciolimites ? \&Itemid=165 \&Lang =pt>. Acesso em 03/02/12.

CANÇADO, Wellington. O muro: "ecolimites" e as favelas do Rio de Janeiro. Minha Cidade, São Paulo, n.09.106, Vitruvius, 2009. Disponível em : <http://www.vitruvius. com.br/revistas/read/minhacidade/09.106/1854>.

CASTRO, Edgardo. El Vocabulario de Michel Foucault: un recorrido alfabético por sus temas, conceptos y autores. Universidad Nacional de Quilmes, 2004.

DE CARLI, Natália e HUMANES, Mariano. An in-human ecolimit: fear and social-spatial segregation. $4^{\text {th }}$ Global Conference Fear, Horror and Terror at the interface, 2010. Disponível em <http://www.inter-disciplinary. net/at-the-interface/evil/fear-horror-terror/projectarchives/4th/session-6-fht-in-spaces-exterior-andinterior/>. Acesso em: 05/04/2012.

FERREIRA, Alvaro. Favelas no Rio de Janeiro: nascimento, expansão, remoção e, agora, exclusão através de muros. Biblio 3W, Revista Bibliográfica de Geografía y Ciencias Sociales, Universidad de Barcelona, Vol. XIV, $\mathrm{n}^{\circ}$ 828, 25 de junio de 2009. Disponível em : <http:// www.ub.es/geocrit/b3w-828.htm>.

HAESBAERT, Rogério. Território, insegurança e risco em tempos de contenção social. In: FERREIRA, A. et al (org.). A Experiência Migrante: entre deslocamentos e reconstruções. Rio de Janeiro: Garamond, 2010, p.537-557.

INSTITUTO DE PESQUISA E PLANEJAMENTO URBANO E REGIONAL - IPPUR/ UFRJ. Relatório de avaliação técnica das propostas de revisão do Plano Diretor Decenal do Rio de Janeiro. Rio de Janeiro: IPPUR/ UFRJ, 2010. Disponível em:< http://www.camara.rj.gov. br/planodiretor/pd2009/relatoriosIPPUR/relatorio_ IPPUR_planodiretor.pdf>. Acesso em: 06/06/2012.

MACHADO, Ana Brasil. Em cima do muro: um cenário para o ecolimite do Santa Marta. Monografia (Bacharelado em Geografia)- Departamento de Geografia/IGEO/UFRJ, Rio de Janeiro, 2009.

MACHADO, Ana Brasil. O muro é a notícia: o discurso da ordem e o ecolimite do Santa Marta. Revista Espaço Aberto, v. 1, n.2, 2011, p.157-166.

MACHADO, Ana Brasil. Os ecolimites como dispositivo para a gestão das descontinuidades internas da cidade do Rio de Janeiro. Dissertação (Mestrado em Geografia) Universidade Federal do Rio de Janeiro/Programa de Pós-Graduação em Geografia, Rio de Janeiro, 2013

PEDROSO, Isabella. O Estado e os Muros: um estudo sobre as políticas destinadas às favelas cariocas através da mídia impressa. Rio de Janeiro, UERJ, Monografia defendida no Programa de Pós-graduação em Ciências Sociais, Curso de Especialização em Sociologia Urbana, 2009. 
REVEL, Judith. Foucault: conceitos essenciais. São Paulo: Claraluz, 2005.

RIO DE JANEIRO. Projeto de Lei 245/09. Institui no Município do Rio de Janeiro regulação para a implementação de ecolimites, 2009.
RIO DE JANEIRO. Lei Complementar 111/2011. Plano Diretor de Desenvolvimento Urbano Sustentável do Município do Rio de Janeiro, 2011.

SANTOS, Milton. Manual de Geografia Urbana. São Paulo: Hucitec, 1981.

\section{Ana Brasil Machado}

Bacharel e licenciada em Geografia pela Universidade Federal do Rio de Janeiro (UFRJ). Mestre em Geografia e doutoranda pela mesma Universidade. Desde 2016, é professora agregada do departamento de Geografia e Meio Ambiente da Pontifícia Universidade Católica do Rio de Janeiro (PUC-Rio). É pesquisadora do grupo Território e Cidadania (Departamento de Geografia/UFRJ). Seus temas de interesse são: limites urbanos, natureza e cidade e espaços públicos.

E-mail: anabrgeo@gmail.com 